\title{
Gender differences in association between uric acid and all-cause mortality in patients with chronic heart failure
}

Viera Stubnova ${ }^{1,2^{*}} \mathbb{D}$, Ingrid Os ${ }^{2,3}$, Aud Høieggen ${ }^{2,3}$, Marit D. Solbu ${ }^{4,5}$, Morten Grundtvig ${ }^{6}$, Arne S. Westheim Dan Atar ${ }^{2,7}$ and Bård Waldum-Grevbo ${ }^{3}$

\begin{abstract}
Background: Elevated serum uric acid (SUA) is associated with poor prognosis in patients with cardiovascular disease, yet it is still not decided whether the role of SUA is causal or only reflects an underlying disease. The purpose of the study was to investigate if SUA was an independent predictor of 5-year all-cause mortality in a propensity score matched cohort of chronic heart failure (HF) outpatients. Furthermore, to assess whether gender or renal function modified the effect of SUA.

Methods: Patients ( $n=4684$ ) from the Norwegian Heart Failure Registry with baseline SUA were included in the study. Individuals in the highest gender-specific SUA quartile were propensity score matched 1:1 with patients in the lowest three SUA quartiles. The propensity score matching procedure created 928 pairs of patients $(73.4 \%$ males, mean age $71.4 \pm 11.5$ years) with comparable baseline characteristics. Kaplan Meier and Cox regression analyses were used to investigate the independent effect of SUA on all-cause mortality.

Results: SUA in the highest quartile was an independent predictor of all-cause mortality in HF outpatients (hazard ratio (HR) 1.19, 95\% confidence interval (Cl) 1.03-1.37, $p$-value 0.021). Gender was found to interact the relationship between SUA and all-cause mortality ( $p$-value for interaction 0.007). High SUA was an independent predictor of all-cause mortality in women (HR 1.65, 95\% Cl 1.24-2.20, p-value 0.001), but not in men (HR 1.06, 95\% Cl 0.89-1.25, $p$-value 0.527). Renal function did not influence the relationship between SUA and all-cause mortality ( $p$-value for interaction 0.539 ).

Conclusions: High SUA was independently associated with inferior 5-year survival in Norwegian HF outpatients. The finding was modified by gender and high SUA was only an independent predictor of 5-year all-cause mortality in women, not in men.
\end{abstract}

Keywords: Uric acid, Heart failure, Gender, Kidney disease, All-cause mortality, Propensity score, Epidemiology

\section{Background}

The relationship between elevated serum uric acid (SUA) and cardiovascular (CV) disease and mortality is well recognized $[1,2]$, yet it is still undecided whether the association reflects a causal inference or whether SUA is a risk marker reflecting the burden of the underlying disease.

SUA, the end product of purine metabolism in humans, is catalysed by xanthine oxidase (XO) and predominantly eliminated by the kidneys [3]. Renal function, gender, race,

\footnotetext{
* Correspondence: viera.stubnova@medisin.uio.no

${ }^{1}$ Finnmark Hospital Trust, Kirkenes, Norway

${ }^{2}$ Institute of Clinical Medicine, University of Oslo, Oslo, Norway

Full list of author information is available at the end of the article
}

and medication may all influence SUA level [2]. In addition, genetic studies have uncovered variants in urate reabsorption and excretion transporters that are responsible for some variation in SUA level [4].

High SUA in heart failure (HF) may result from impaired oxidative metabolism causing accumulation of uric acid precursors and increased $\mathrm{XO}$ activation [5] as well as from decreased renal elimination as chronic kidney disease (CKD) is highly prevalent [6].

High SUA levels have been found to be related to incident HF [7-10] and to be associated with poor outcomes in HF patients [11-14]. An association between SUA and incident, prevalent and progressive CKD has also been

(c) The Author(s). 2019 Open Access This article is distributed under the terms of the Creative Commons Attribution 4.0 International License (http://creativecommons.org/licenses/by/4.0/), which permits unrestricted use, distribution, and reproduction in any medium, provided you give appropriate credit to the original author(s) and the source, provide a link to the Creative Commons license, and indicate if changes were made. The Creative Commons Public Domain Dedication waiver (http://creativecommons.org/publicdomain/zero/1.0/) applies to the data made available in this article, unless otherwise stated. 
detected [15-17] but the results concerning effect of SUA on mortality in CKD patients are inconsistent [18-21].

Cardiovascular risk factors and outcomes differ between men and women [22]. Gender differences are also apparent in HF patients, both with regard to aetiology, left ventricle ejection fraction (LVEF) and prognosis [23-26]. The association between SUA and CV disease outcomes appears to be more pronounced in women than in men $[7,27,28]$ but the role of gender in the relationship between SUA and survival of HF patients is not yet clearly determined.

Reducing the effect of confounding is crucial when estimating associations in observational studies. Propensity score matching is a statistical method that accounts for confounding variables in a different manner than traditional multivariate Cox proportional hazards model and might be a superior method [29].

The aim of the current study was to examine whether SUA is an independent predictor of all-cause mortality in a propensity score matched cohort of Norwegian HF outpatients. Furthermore, we aimed to analyse if the effect of SUA on all-cause mortality is modified by gender or renal function.

\section{Methods}

\section{The Norwegian heart failure registry}

The Norwegian Heart Failure Registry has collected data on outpatients referred to HF clinics in Norwegian hospitals since 2000. By February 2012, a total of 6675 patients were enrolled by $25 \mathrm{HF}$ clinics in different Norwegian regions that cover about half of Norway's population. The participating HF clinics were run by cardiologists and specialized nurses. Patients were registered after they had been diagnosed with chronic HF of any aetiology following the guidelines of the European Society of Cardiology (ESC) [30, 31]. Three visits were recorded. At the time of the first visit (baseline), medical history, physical examination, echocardiography, New York Heart Association (NYHA) functional class, laboratory results, and the medical management of HF were recorded. The last adjustment visit was recorded at stable follow-up, after the multidisciplinary team had optimized the treatment and the patient had participated in an educational program. At the time of the third visit, arranged 6 months after the last adjustment visit, patient's health condition was reassessed, as well as medication and laboratory results. Mortality data are retrieved yearly from Statistics Norway.

\section{Study population}

A total of $4953(74.2 \%)$ patients in the Norwegian Heart Failure Registry had available baseline measurements of SUA and were eligible for the study. The patients in each reporting hospital were grouped into gender specific SUA quartiles, as the participating hospitals used different laboratory assays for SUA analyses and the recommended reference range of SUA differs for women and men (women 18-49 years: $155-350 \mu \mathrm{mol} / \mathrm{l}$, women over 50 years: $155-400 \mu \mathrm{mol} / \mathrm{l}$, men: $230-480 \mu \mathrm{mol} / \mathrm{l}$ ) [32]. Subjects from hospitals with less than 40 registered subjects were excluded to achieve proper stratification. Consequently, 4684 patients from 19 hospitals were stratified and included in the analyses. Finally, patients in each SUA quartile were merged together across hospitals and gender, comprising about 1180 subjects in each group.

\section{Definitions}

Renal function was expressed as estimated glomerular filtration rate (eGFR) and calculated using the Chronic Kidney Disease Epidemiology Collaboration (CKD-EPI) equation [33]. Reduced renal function was defined as eGFR $<60 \mathrm{ml} / \mathrm{min} / 1.73 \mathrm{~m}^{2}$.

Based on 2016 ESC Guidelines on HF [34], LVEF was defined as reduced at $<40 \%$ and as preserved at $\geq 50 \%$.

Diagnosis of hypertension was based on information on antihypertensive treatment.

Daily doses of angiotensin-converting enzyme inhibitors (ACEi) were converted to enalapril equivalent doses (enalapril $20 \mathrm{mg}=$ lisinopril $20 \mathrm{mg}$ = ramipril $10 \mathrm{mg}=$ captopril $100 \mathrm{mg}$ ), and then expressed as percent of enalapril target dose. Target dose of enalapril was defined as $20 \mathrm{mg}$ per day. Daily doses of loop diuretics were converted to furosemide equivalent doses (furosemide $40 \mathrm{mg}$ = bumetanide $1 \mathrm{mg}$ ). Daily doses of $\beta$-blockers were converted to metoprolol equivalent doses (metoprolol $200 \mathrm{mg}=$ bisoprolol $10 \mathrm{mg}$ = carvedilol $50 \mathrm{mg}$ = atenolol $100 \mathrm{mg}$ ).

\section{Statistical analysis}

Continuous variables were expressed as mean \pm standard deviation and categorical variables as frequencies (percentage). Differences in continuous variables were compared by one-way analysis of variance and Student t-test as required. Similarly, differences in categorical variables were compared by $\chi^{2}$ test. The two-tailed significance level test was set to $p<0.05$.

An individual propensity score, the likelihood of SUA being in the highest quartile, was obtained for each patient using a multivariate logistic regression model. Baseline variables found to be associated with SUA in the highest quartile $(p$-value $<0.10)$ and variables that could potentially confound the relationship between SUA and mortality were chosen as independent variables when calculating the propensity score. The following 16 covariates were entered in the model: gender, age, body mass index (BMI), smoking, diabetes mellitus, claudication and/or previous stroke, systolic blood pressure, NYHA functional class, use of renin-angiotensin-system (RAS)-blocking agents, $\beta$-blocker dose, diuretic dose, use of statin, eGFR, haemoglobin, serum sodium and serum potassium. Patients with SUA in the fourth quartile were then matched 1:1 to patients 
Table 1 Baseline characteristics of HF outpatients before and after propensity score matching, by SUA quartiles

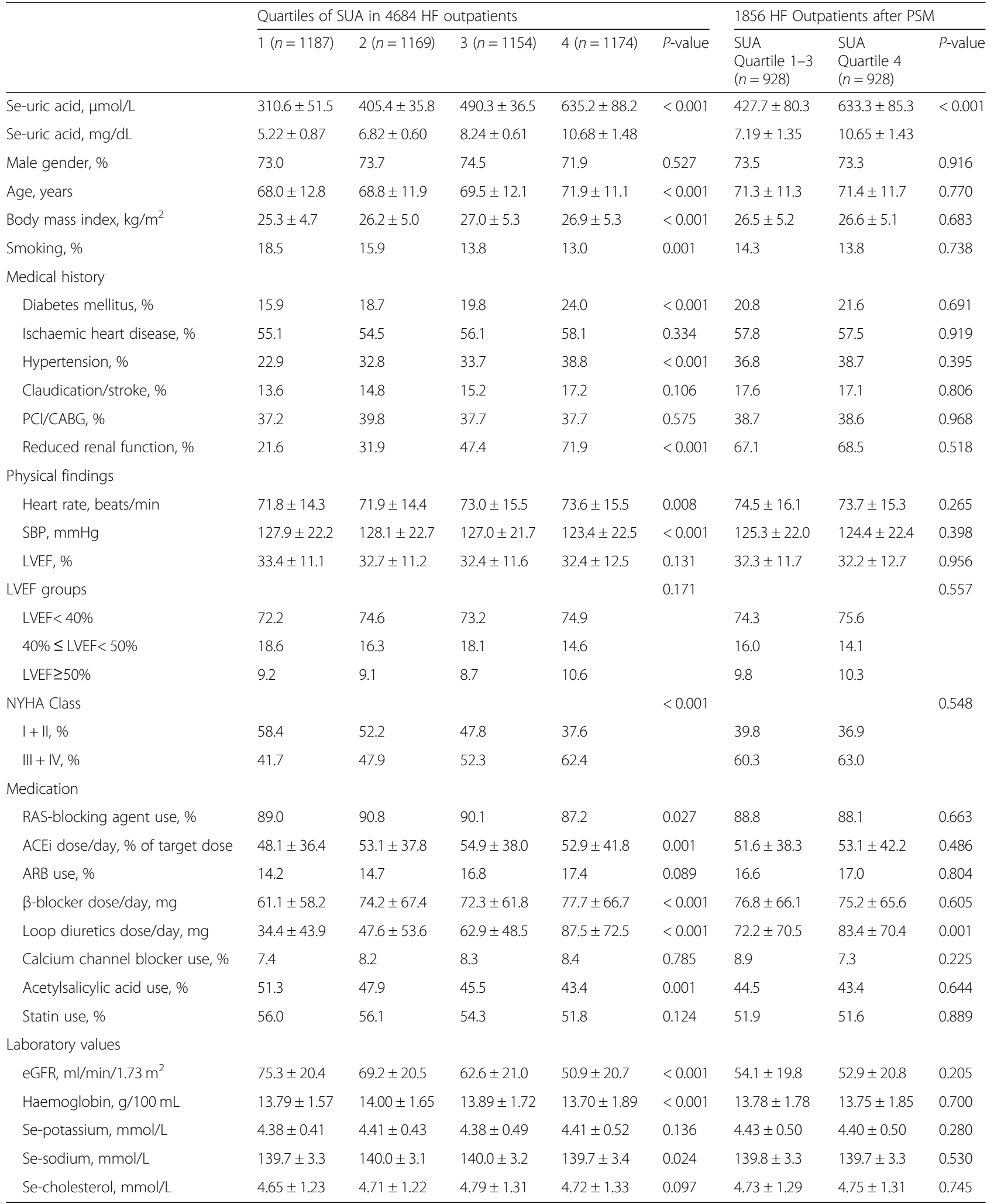

Values are expressed as mean \pm SD or percent. ACEi dose/day, percent of daily enalapril equivalent target dose; ARB, angiotensin receptor blocker; $\beta$-blocker dose/ day, daily metoprolol equivalent dose; eGFR, estimated glomerular filtration rate; HF, heart failure; LVEF, left ventricular ejection fraction; NYHA, New York Heart Association; PCl/CABG, percutaneous coronary intervention and/or coronary artery bypass graft; PSM, propensity score matching; RAS-blocking agent, reninangiotensin system blocking agent; SBP, systolic blood pressure; SUA, serum uric acid 
with SUA in quartiles $1-3$ on the propensity score, using match tolerance of 0.05 with no replacement and preference to exact match.

Five-year survival curves were presented using KaplanMeier statistics. Univariate Cox proportional hazards model was used in the propensity score matched cohort and presented as hazard ratio (HR) and 95\% confidential interval (95\% CI). Due to the limited number of female patients, multivariable Cox proportional hazards model was used when evaluating the effect of SUA on all-cause mortality in the gender-stratified model. Baseline variables found to be associated with SUA in the highest quartile in women ( $p$-value $<0.10)$ were included in the multivariate model: age, BMI, smoking, ischaemic heart disease, diabetes mellitus, hypertension, NYHA functional class, systolic blood pressure, LVEF, use of RAS-blocking agents, $\beta$-blocker dose, diuretic dose, eGFR, and serum sodium.

All statistical analyses were performed using IBM SPSS Statistics version 25 (IBM SPSS Statistics, New York, USA). Kaplan Meier survival curves were obtained using STATA/SE version 14.1 (StataCorp LP, Texas, USA).

\section{Results}

Baseline characteristics and propensity score matching

Baseline characteristics of the 4684 included HF outpatients are presented by SUA quartiles in Table 1. The mean age was $69.6 \pm 12.2$ years and $73.3 \%$ were males. Patients in higher SUA quartiles were more prone to be older, to have a history of diabetes and hypertension, more severe HF symptoms, higher BMI and worse renal function compared to patients in the lower SUA quartiles. They used higher doses of diuretics and $\beta$-blockers and were less likely to use RAS-blocking agents and acetylsalicylic acid. The median follow-up was 50 (interquartile range (IQR) 27, 78) months.
Kaplan-Meier survival curves for SUA in quartiles 1-3 were almost superimposable and all-cause mortality for individuals with SUA in quartile 4 was significantly greater than for those with SUA in quartiles 1-3 (log-rank < 0.001, Fig. 1). Individuals with SUA in the lowest three quartiles were therefore all selected to be potential controls in the propensity matched model. A total of 928 subjects with SUA in quartile 4 were matched 1:1 by propensity score to subjects with SUA in quartiles 1-3. Baseline characteristics of the 1856 propensity score matched subjects were well-balanced (Table 1).

\section{Survival analyses and outcomes based on SUA level}

SUA in the highest quartile was an independent predictor of all-cause mortality in HF outpatients (HR 1.19, 95\% CI 1.03-1.37, $p$-value 0.021, Fig. 2).

Gender was found to interact the relationship between SUA and all-cause mortality in the propensity matched model ( $p$-value for interaction 0.007). Differences in the survival of HF outpatients depending on gender and SUA quartile are depicted in Kaplan-Meier survival curves in Fig. 3. High SUA was an independent predictor of all-cause mortality in women (HR 1.65, 95\% CI 1.242.20, $p$-value 0.001 ) but not in men (HR 1.06, 95\% CI $0.89-1.25, p$-value 0.527). Renal function did not interact the relationship between SUA and all-cause mortality ( $p$-value for interaction 0.539).

Women and men with SUA in the highest quartile differed both in age, comorbidity, medication, and physical and laboratory findings from those with lower SUA (Table 2). The number of female patients was limited and a gender-stratified propensity matched model was not possible. Subsequently, gender specific multivariate Cox proportional hazard model analyses in the subgroups of 1251 female and 3433 male HF outpatients were performed

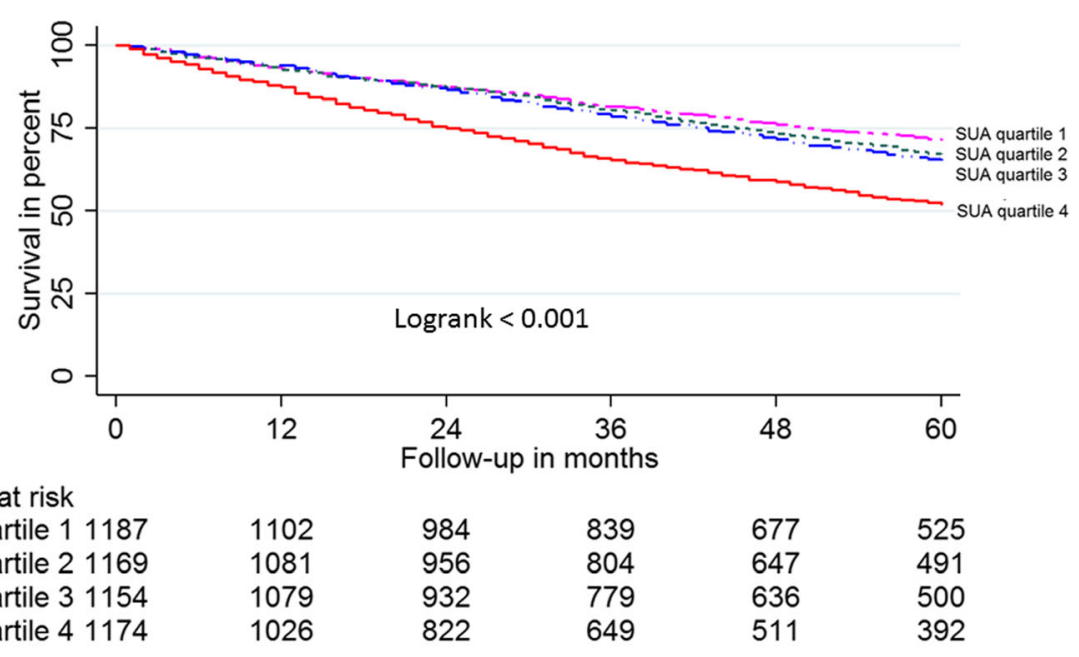

Fig. 1 Kaplan-Meier survival plot of $4684 \mathrm{HF}$ outpatients according to SUA quartile 


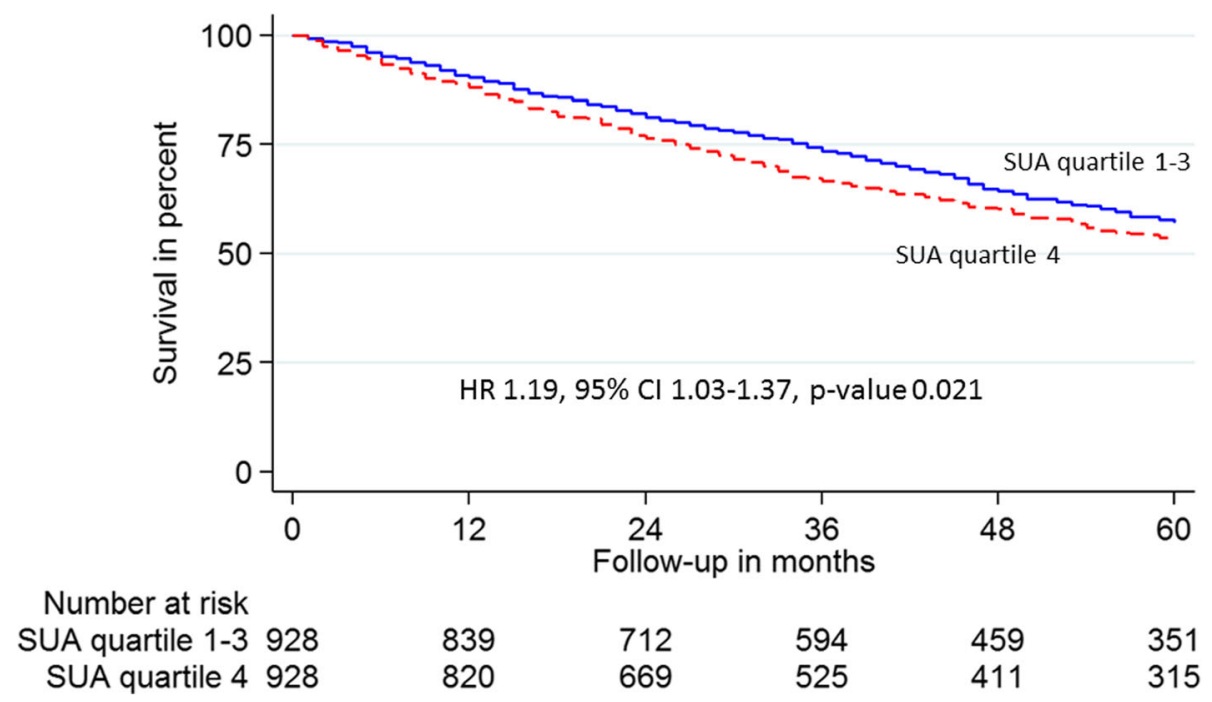

Fig. 2 Kaplan-Meier survival plot of $1856 \mathrm{HF}$ outpatients propensity score matched by SUA in quartile 4

to further explore gender differences in the prognostic value of SUA on survival. In the subgroup of female HF outpatients, SUA in the highest quartile was confirmed to be an independent predictor of all-cause mortality (HR $1.51,95 \%$ CI 1.13-2.02, $p$-value 0.005). On the contrary, SUA did not independently predict all-cause mortality in the subgroup of male HF outpatients (HR 1.10, 95\% CI $0.94-1.30, p$-value 0.249 ).

\section{Discussion}

The current study demonstrates that high level of SUA was an independent predictor of 5-year all-cause mortality in patients with chronic HF. The finding was gender specific and only found in women. To our knowledge, this is the first propensity score matched study to report the gender modifying effect on the relationship between SUA and all-cause mortality in chronic HF. The predictive value of SUA on mortality was not modified by renal function.
Other studies have found an association between high levels of SUA and poor outcome in chronic HF patients $[13,21,35-37]$, still the causal relationship is considered undecided. We report SUA in the fourth quartile to be an independent predictor of all-cause mortality selectively in women, both in the propensity score matched model and multivariate Cox regression model.

Gender differences in the effect of SUA on outcomes have been reported previously in patients with CV disease. In hypertensive patients with left ventricular hypertrophy, the association between SUA and CV events was reported to be stronger in women than in men [28]. A study of patients with acute coronary syndrome showed that SUA was predictive of CV events in women but not in men [38]. Similarly, in a population based survey, SUA was found to be an independent predictor of mortality in women only [27]. Our results now expand the evidence for gender differences in the effect of SUA also to be valid in HF outpatients.

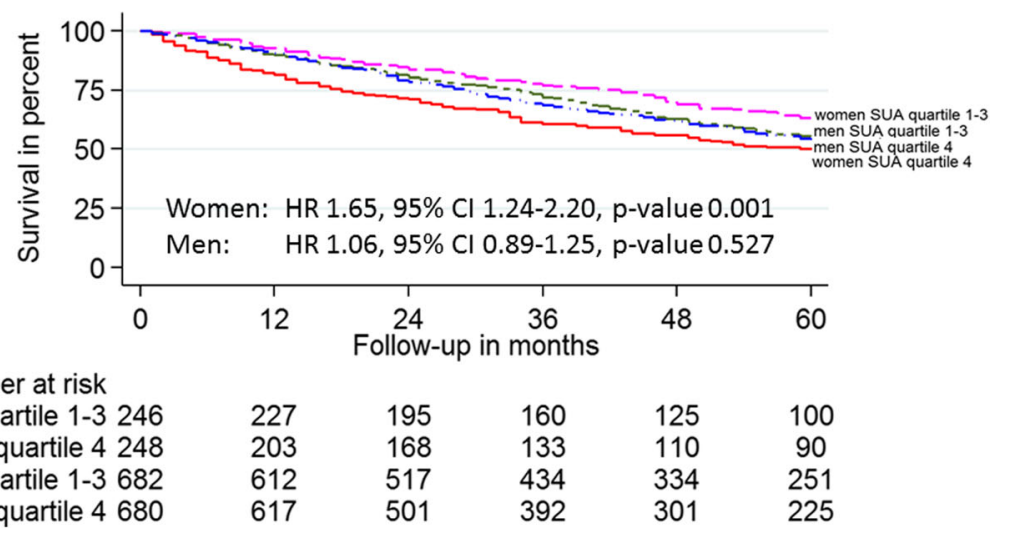

Fig. 3 Kaplan-Meier survival plot of propensity score matched HF outpatients according to gender and SUA quartile 


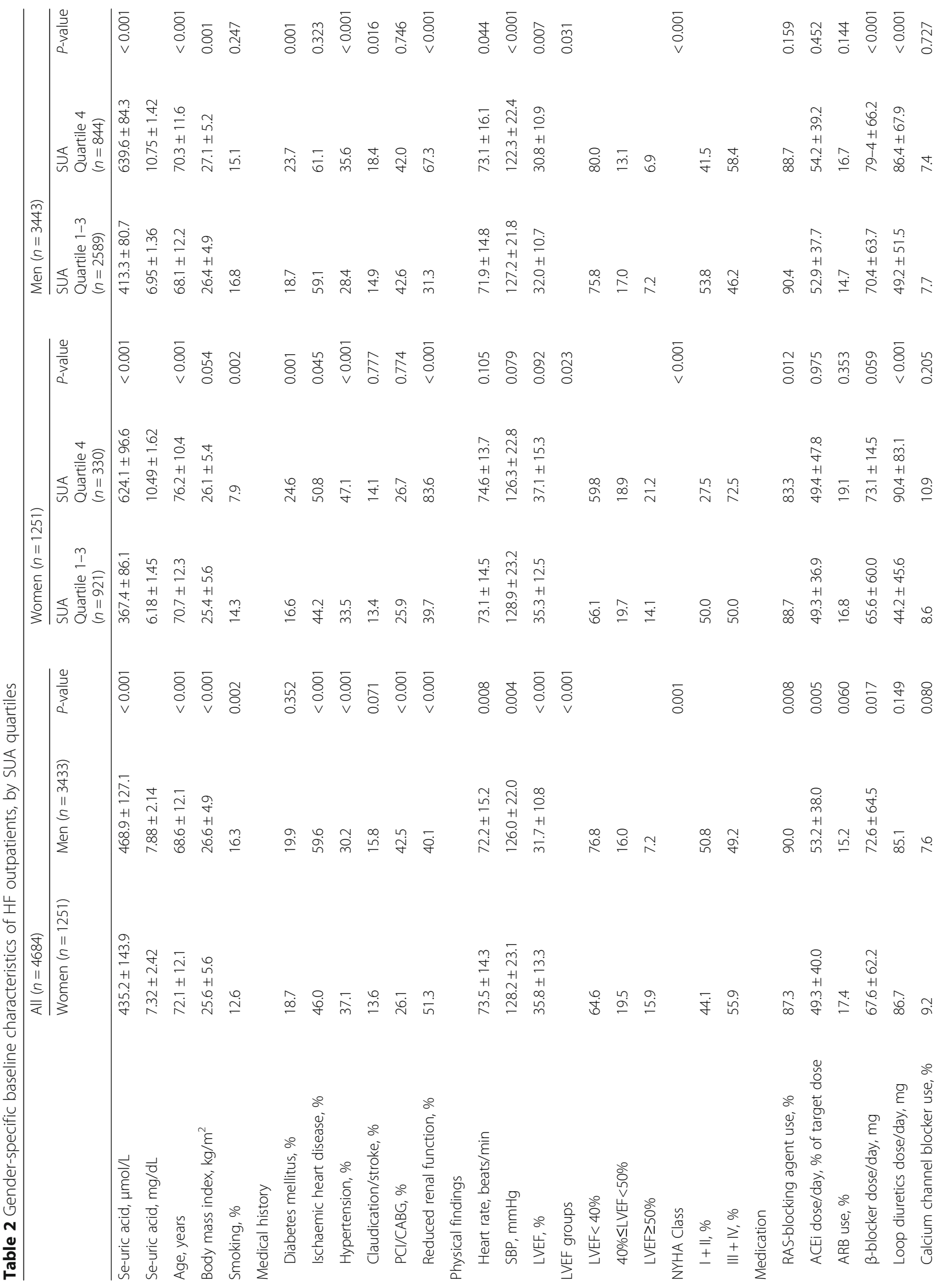




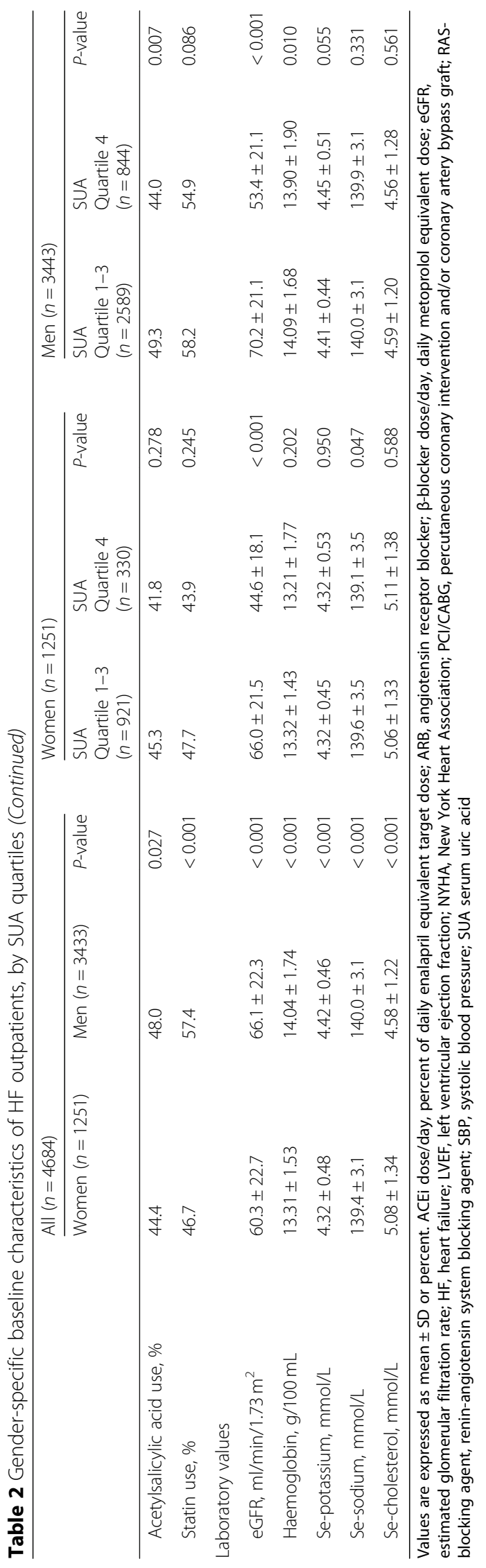


In most previous studies assessing differences in survival between men and women with HF, women have been reported to have better survival than men [25, 39-44]. Sex hormones affect myocardial calcium handling, nitric oxide, glucose and fatty metabolism as well as cardiac fibrosis, and may participate in the mechanisms for differences between female and male failing hearts [26]. SUA is a potent antioxidant but at the same time, SUA and XO lead to reduced nitric oxide bioavailability, ensuing endothelial dysfunction, inflammation and vasoconstriction [45]. Menopause has been found to be associated with increasing SUA, possibly due to altered effect of oestrogen on renal tubular handling of uric acid [46]. We did not have information on menopausal status in female HF outpatients in the current study, but the mean age of $72.1 \pm 12.1$ years implies that the great majority were postmenopausal. Our study revealed distinct differences between women and men with SUA in quartile 4 with regard to age, type, symptoms and treatment of HF, as well as comorbidity and renal function. Still, both the propensity score matched model and multivariate Cox regression model identified SUA in the highest quartile to be a predictor of all-cause mortality in women independently of the above mentioned confounding variables. The mechanisms for the deteriorating effect of high SUA on survival selectively in postmenopausal women need to be further explored, yet our findings may imply SUA being a future treatment target in female HF patients. Urate-lowering therapy is currently not recommended in asymptomatic hyperuricemia due to limited benefit-risk data in non-gout diseases [47]. Nevertheless, XO-inhibiting therapy has been shown to have beneficial effects in some patient groups [48]. In HF patients with hyperuricemia, XO-inhibition did not improve survival, but it is noteworthy that the study was not gender stratified and only of 24-week duration [49].

Renal function did not modify the effect of SUA on all-cause mortality in the present study. This corroborates the observation by Anker et al. [13] who also found SUA to be a predictor of poor outcome in HF independent of renal function, while Filippatos et al. [21] found SUA to be associated with poor outcome only in HF patients without CKD. Studies exploring SUA impact in patients with CKD show inconsistent results [18-20].

Some limitations of our study need to be considered. Because of various laboratory assays for SUA analyses in the reporting hospitals, we grouped patients in each hospital into gender-specific SUA quartiles. Small groups may cause a systematic error and therefore we did not include patients from hospitals with less than 40 registered individuals. On the other hand, we might have introduced a selection bias by excluding some hospitals. Patients in each SUA quartile were merged together across hospitals and gender, eventually leading to some overlapping SUA values in the four quartiles.
We used both propensity score method and multivariate Cox regression method to reduce the bias by confounding. Propensity score matching is an increasingly used method that mimics some characteristics of randomized control trials (RCT) and makes it possible to directly compare outcomes in the two studied groups [29]. We used propensity score matching when assessing the impact of high SUA on survival in all HF outpatients. Propensity score for having SUA in the highest quartile was estimated based on 16 measured baseline variables. Two groups of patients were established based on propensity score, differing in the presence or absence of SUA in the fourth quartile and, similarly to RCTs, we could then directly compare survival in the groups. Distribution of baseline characteristic in the propensity matched groups was well-balanced except for daily doses of diuretics. However, the difference was minor and is unlikely to explain the disparity in survival. Furthermore, the large size of the study population and the high number of variables used for estimation of propensity score and the fact that nearly $80 \%$ of patients with SUA in the highest quartile were propensity score matched should ensure reliability of our results. In the gender stratified analyses, we used multivariate Cox proportional hazard model to correct for the confounding variables as propensity score matching would lead to small size of the examined groups and thus could possibly introduce a selection bias. Yet, neither propensity score matching nor multivariate Cox proportional hazards method can correct for unmeasured confounding variables.

The current study is observational and therefore restricted to the existing data in the Norwegian Heart Failure Registry. We could not influence selection of the collected variables. Information on alcohol consumption, losartan use, hormone replacement therapy, the use of SUA lowering drugs, thyroid function, and triglycerides level could have added valuable information. At the same time, the observational nature of this study is among its strengths as the included patients represent a relatively unselected population in contrast to highly selected subjects in RCTs.

\section{Conclusions}

SUA in the highest quartile was independently associated with inferior 5-year survival in Norwegian HF outpatients. The finding was modified by gender and high SUA was only an independent predictor of 5-year all-cause mortality in women but not in men. Our findings indicate that SUA might be a therapeutic target selectively in female HF patients. Renal function did not modify the effect of SUA on all-cause mortality.

\section{Abbreviations}

ACEi: Angiotensin-converting enzyme inhibitors; ARB: Angiotensin II receptor blocker; BMI: Body mass index; Cl: Confidence interval; CKD: Chronic kidney disease; CKD-EPI: Chronic Kidney Disease Epidemiology Collaboration;

CV: Cardiovascular; eGFR: Estimated glomerular filtration rate; ESC: European 
Society of Cardiology; HF: Heart failure; HR: Hazard ratio; IQR: Interquartile range; LVEF: Left ventricle ejection fraction; NYHA: New York Heart Association; PCI/CABG: Percutaneous coronary intervention and/or coronary artery bypass graft; RAS: Renin-angiotensin system; SUA: Serum uric acid; XO: Xanthine oxidase

\section{Acknowledgements}

The authors are grateful to all HF clinics that contribute with high-quality data to the Norwegian Heart Failure Registry.

\section{Funding}

The first author is a research fellow funded by the South-Eastern Norway Regional Health Authority.

\section{Availability of data and materials}

The data that support the findings of this study are available from the Norwegian Heart Failure Registry but restrictions apply to the availability of these data, which were used under license for the current study, and so are not publicly available. Data are however available from the authors upon reasonable request and with permission of the Norwegian Heart Failure Registry.

\section{Authors' contributions}

VS, BWG and 10 are responsible for the study design. MG provided the data on behalf of the Norwegian Heart Failure Registry. VS and BWG performed the statistical analyses and VS wrote the manuscript. VS, BWG, IO, AH, MDS, ASW, MG and DA have all participated in interpretation of the results and critically revised and approved the final version of the manuscript. All authors take public responsibility for the content.

\section{Ethics approval and consent to participate}

All patients enrolled in the Norwegian Heart Failure Registry had given written informed consent prior to inclusion in the database. The study was approved by the Regional Committee of Medical Research Ethics South East (Ref. no. 2014/1449).

\section{Consent for publication}

Not applicable.

\section{Competing interests}

The authors declare that they have no competing interests.

\section{Publisher's Note}

Springer Nature remains neutral with regard to jurisdictional claims in published maps and institutional affiliations.

\section{Author details}

${ }^{1}$ Finnmark Hospital Trust, Kirkenes, Norway. ${ }^{2}$ Institute of Clinical Medicine, University of Oslo, Oslo, Norway. ${ }^{3}$ Department of Nephrology, Oslo University Hospital, Ullevål, Oslo, Norway. ${ }^{4}$ Section of Nephrology, University Hospital of North Norway, Tromsø, Norway. ${ }^{5}$ Metabolic and Renal Research Group, UiT The Arctic University of Norway, Tromsø, Norway. ${ }^{6}$ Department of Medicine, Innlandet Hospital Trust, Lillehammer, Norway. ${ }^{7}$ Department of Cardiology, Oslo University Hospital, Ullevål, Oslo, Norway.

\section{Received: 18 May 2018 Accepted: 21 December 2018}

Published online: 05 January 2019

\section{References}

1. Feig DI, Kang DH, Johnson RJ. Uric acid and cardiovascular risk. N Engl J Med. 2008;359(17):1811-21.

2. Wu AH, Gladden JD, Ahmed M, Ahmed A, Filippatos G. Relation of serum uric acid to cardiovascular disease. Int J Cardiol. 2016;213:4-7.

3. Maesaka JK, Fishbane S. Regulation of renal urate excretion: a critical review. Am J Kidney Dis. 1998;32(6):917-33.

4. Benn CL, Dua P, Gurrell R, Loudon P, Pike A, Storer RI, Vangjeli C. Physiology of hyperuricemia and urate-lowering treatments. Front Med. 2018;5:160.

5. Leyva F, Anker S, Swan JW, Godsland IF, Wingrove CS, Chua TP, Stevenson JC, Coats AJ. Serum uric acid as an index of impaired oxidative metabolism in chronic heart failure. Eur Heart J. 1997;18(5):858-65.
6. Waldum B, Westheim AS, Sandvik L, Flonaes B, Grundtvig M, Gullestad L, Hole T, Os I. Renal function in outpatients with chronic heart failure. J Card Fail. 2010;16(5):374-80

7. Holme I, Aastveit AH, Hammar N, Jungner I, Walldius G. Uric acid and risk of myocardial infarction, stroke and congestive heart failure in 417,734 men and women in the apolipoprotein MOrtality RISk study (AMORIS). J Intern Med. 2009;266(6):558-70

8. Ekundayo OJ, Dell'Italia LJ, Sanders PW, Arnett D, Aban I, Love TE, Filippatos G, Anker SD, Lloyd-Jones DM, Bakris G, et al. Association between hyperuricemia and incident heart failure among older adults: a propensitymatched study. Int J Cardiol. 2010;142(3):279-87.

9. Eisen A, Benderly M, Goldbourt U, Haim M. Is serum uric acid level an independent predictor of heart failure among patients with coronary artery disease? Clin Cardiol. 2013;36(2):110-6.

10. Krishnan E. Hyperuricemia and incident heart failure. Circ Heart fail. 2009; 2(6):556-62

11. Palazzuoli A, Ruocco G, Pellegrini M, Beltrami M, Giordano N, Nuti R, McCullough PA. Prognostic significance of hyperuricemia in patients with acute heart failure. Am J Cardiol. 2016;117(10):1616-21.

12. Pascual-Figal DA, Hurtado-Martinez JA, Redondo B, Antolinos MJ, Ruiperez JA, Valdes M. Hyperuricaemia and long-term outcome after hospital discharge in acute heart failure patients. Eur J Heart Fail. 2007;9(5):518-24.

13. Anker SD, Doehner W, Rauchhaus M, Sharma R, Francis D, Knosalla C, Davos $\mathrm{CH}$, Cicoira M, Shamim W, Kemp M, et al. Uric acid and survival in chronic heart failure: validation and application in metabolic, functional, and hemodynamic staging. Circulation. 2003;107(15):1991-7.

14. Tamariz L, Harzand A, Palacio A, Verma S, Jones J, Hare J. Uric acid as a predictor of all-cause mortality in heart failure: a meta-analysis. Congest Heart Fail. 2011;17(1):25-30.

15. Chonchol M, Shlipak MG, Katz R, Sarnak MJ, Newman AB, Siscovick DS, Kestenbaum B, Carney JK, Fried LF. Relationship of uric acid with progression of kidney disease. Am J Kidney Dis. 2007:50(2):239-47.

16. Obermayr RP, Temml C, Gutjahr G, Knechtelsdorfer M, Oberbauer R, KlauserBraun R. Elevated uric acid increases the risk for kidney disease. J Am Soc Nephrol. 2008;19(12):2407-13.

17. Weiner DE, Tighiouart H, Elsayed EF, Griffith JL, Salem DN, Levey AS. Uric acid and incident kidney disease in the community. J Am Soc Nephrol. 2008;19(6):1204-11.

18. Madero M, Sarnak MJ, Wang X, Greene T, Beck GJ, Kusek JW, Collins AJ, Levey AS, Menon V. Uric acid and long-term outcomes in CKD. Am J Kidney Dis. 2009;53(5):796-803.

19. Suliman ME, Johnson RJ, Garcia-Lopez E, Qureshi AR, Molinaei H, Carrero JJ, Heimburger O, Barany P, Axelsson J, Lindholm B, et al. J-shaped mortality relationship for uric acid in CKD. Am J Kidney Dis. 2006;48(5):761-71.

20. Navaneethan SD, Beddhu S. Associations of serum uric acid with cardiovascular events and mortality in moderate chronic kidney disease. Nephrol Dial Transplant. 2009;24(4):1260-6.

21. Filippatos GS, Ahmed MI, Gladden JD, Mujib M, Aban IB, Love TE, Sanders PW, Pitt B, Anker SD, Ahmed A. Hyperuricaemia, chronic kidney disease, and outcomes in heart failure: potential mechanistic insights from epidemiological data. Eur Heart J. 2011;32(6):712-20.

22. Maas AH, van der Schouw YT, Regitz-Zagrosek V, Swahn E, Appelman YE, Pasterkamp G, Ten Cate H, Nilsson PM, Huisman MV, Stam HC, et al. Red alert for women's heart: the urgent need for more research and knowledge on cardiovascular disease in women: proceedings of the workshop held in Brussels on gender differences in cardiovascular disease, 29 September 2010. Eur Heart J. 2011:32(11):1362-8.

23. Lenzen MJ, Rosengren A, Scholte op Reimer WJ, Follath F, Boersma E, Simoons ML, Cleland JG, Komajda M. Management of patients with heart failure in clinical practice: differences between men and women. Heart. 2008;94(3):e10.

24. Cleland JG, Swedberg K, Follath F, Komajda M, Cohen-Solal A, Aguilar JC, Dietz R, Gavazzi A, Hobbs R, Korewicki J, et al. The EuroHeart failure survey programme-- a survey on the quality of care among patients with heart failure in Europe. Part 1: patient characteristics and diagnosis. Eur Heart J. 2003;24(5):442-63.

25. Ho KK, Anderson KM, Kannel WB, Grossman W, Levy D. Survival after the onset of congestive heart failure in Framingham heart study subjects. Circulation. 1993:88(1):107-15.

26. Regitz-Zagrosek V, Oertelt-Prigione S, Seeland U, Hetzer R. Sex and gender differences in myocardial hypertrophy and heart failure. Circ J. 2010;74(7): 1265-73. 
27. Freedman DS, Williamson DF, Gunter EW, Byers T. Relation of serum uric acid to mortality and ischemic heart disease. The NHANES I epidemiologic follow-up study. Am J Epidemiol. 1995;141(7):637-44.

28. Hoieggen A, Alderman MH, Kjeldsen SE, Julius S, Devereux RB, De Faire U, Fyhrquist F, Ibsen H, Kristianson K, Lederballe-Pedersen O, et al. The impact of serum uric acid on cardiovascular outcomes in the LIFE study. Kidney Int. 2004;65(3):1041-9.

29. Austin PC. An introduction to propensity score methods for reducing the effects of confounding in observational studies. Multivar Behav Res. 2011;46(3):399-424.

30. Remme WJ, Swedberg K. Task force for the D, treatment of chronic heart failure ESoC: guidelines for the diagnosis and treatment of chronic heart failure. Eur Heart J. 2001;22(17):1527-60.

31. McMurray JJ, Adamopoulos S, Anker SD, Auricchio A, Bohm M, Dickstein K, Falk V, Filippatos G, Fonseca C, Gomez-Sanchez MA, et al. ESC guidelines for the diagnosis and treatment of acute and chronic heart failure 2012: the task force for the diagnosis and treatment of acute and chronic heart failure 2012 of the European Society of Cardiology. Developed in collaboration with the heart failure association (HFA) of the ESC. Eur J Heart Fail. 2012;14(8):803-69.

32. Rustad P, Felding P, Franzson L, Kairisto V, Lahti A, Martensson A, Hyltoft Petersen $P$, Simonsson $P$, Steensland $H$, Uldall A. The Nordic reference interval project 2000: recommended reference intervals for 25 common biochemical properties. Scand J Clin Lab Invest. 2004;64(4):271-84.

33. Levey AS, Stevens LA, Schmid CH, Zhang YL, Castro AF 3rd, Feldman HI, Kusek JW, Eggers P, Van Lente F, Greene T, et al. A new equation to estimate glomerular filtration rate. Ann Intern Med. 2009;150(9):604-12.

34. Ponikowski $P$, Voors AA, Anker SD, Bueno H, Cleland JG, Coats AJ, Falk V, Gonzalez-Juanatey JR, Harjola VP, Jankowska EA, et al. 2016 ESC guidelines for the diagnosis and treatment of acute and chronic heart failure: the task force for the diagnosis and treatment of acute and chronic heart failure of the European Society of Cardiology (ESC). Developed with the special contribution of the heart failure association (HFA) of the ESC. Eur J Heart Fail. 2016:18(8):891-975.

35. Jankowska EA, Ponikowska B, Majda J, Zymlinski R, Trzaska M, Reczuch K, Borodulin-Nadzieja L, Banasiak W, Ponikowski P. Hyperuricaemia predicts poor outcome in patients with mild to moderate chronic heart failure. Int J Cardiol. 2007;115(2):151-5.

36. von Lueder TG, Girerd N, Atar D, Agewall S, Lamiral Z, Kanbay M, Pitt B, Dickstein K, Zannad F, Rossignol P, et al. Serum uric acid is associated with mortality and heart failure hospitalizations in patients with complicated myocardial infarction: findings from the high-risk myocardial infarction database initiative. Eur J Heart Fail. 2015;17(11):1144-51.

37. Wu AH, Ghali JK, Neuberg GW, O'Connor CM, Carson PE, Levy WC. Uric acid level and allopurinol use as risk markers of mortality and morbidity in systolic heart failure. Am Heart J. 2010;160(5):928-33.

38. Kawabe M, Sato A, Hoshi T, Sakai S, Hiraya D, Watabe H, Kakefuda Y, Ishibashi M, Abe D, Takeyasu N, et al. Gender differences in the association between serum uric acid and prognosis in patients with acute coronary syndrome. J Cardiol. 2016;67(2):170-6.

39. Alla F, Al-Hindi AY, Lee CR, Schwartz TA, Patterson JH, Adams KF Jr. Relation of sex to morbidity and mortality in patients with heart failure and reduced or preserved left ventricular ejection fraction. Am Heart J. 2007;153(6):1074-80.

40. Adams KF Jr, Sueta CA, Gheorghiade M, O'Connor CM, Schwartz TA, Koch GG, Uretsky B, Swedberg K, McKenna W, Soler-Soler J, et al. Gender differences in survival in advanced heart failure. Insights from the FIRST study. Circulation. 1999;99(14):1816-21.

41. O'Meara E, Clayton T, McEntegart MB, McMurray JJ, Pina IL, Granger CB, Ostergren J, Michelson EL, Solomon SD, Pocock S, et al. Sex differences in clinical characteristics and prognosis in a broad spectrum of patients with heart failure: results of the candesartan in heart failure: assessment of reduction in mortality and morbidity (CHARM) program. Circulation. 2007;115(24):3111-20.

42. Ghali JK, Krause-Steinrauf HJ, Adams KF, Khan SS, Rosenberg YD, Yancy CW, Young JB, Goldman S, Peberdy MA, Lindenfeld J. Gender differences in advanced heart failure: insights from the BEST study. J Am Coll Cardiol. 2003;42(12):2128-34

43. Sakata Y, Miyata S, Nochioka K, Miura M, Takada T, Tadaki S, Takahashi J, Shimokawa H. Gender differences in clinical characteristics, treatment and long-term outcome in patients with stage C/D heart failure in Japan. Report from the CHART-2 study. Circ J. 2014;78(2):428-35.
44. Ahmed MI, Lainscak M, Mujib M, Love TE, Aban I, Pina IL, Aronow WS, Bittner V, Ahmed A. Gender-related dissociation in outcomes in chronic heart failure: reduced mortality but similar hospitalization in women. Int J Cardiol. 2011;148(1):36-42.

45. Puddu P, Puddu GM, Cravero E, Vizioli L, Muscari A. Relationships among hyperuricemia, endothelial dysfunction and cardiovascular disease: molecular mechanisms and clinical implications. J Cardiol. 2012;59(3):235-42.

46. Hak AE, Choi HK. Menopause, postmenopausal hormone use and serum uric acid levels in US women--the third National Health and nutrition examination survey. Arthritis Res Ther. 2008;10(5):R116.

47. Stamp L, Dalbeth N. Urate-lowering therapy for asymptomatic hyperuricaemia: a need for caution. Semin Arthritis Rheum. 2017;46(4):457-64.

48. Bredemeier M, Lopes LM, Eisenreich MA, Hickmann S, Bongiorno GK, d'Avila R, Morsch ALB, da Silva Stein F, Campos GGD. Xanthine oxidase inhibitors for prevention of cardiovascular events: a systematic review and meta-analysis of randomized controlled trials. BMC Cardiovasc Disord. 2018;18(1):24.

49. Givertz MM, Anstrom KJ, Redfield MM, Deswal A, Haddad H, Butler J, Tang WH, Dunlap ME, LeWinter MM, Mann DL, et al. Effects of xanthine oxidase inhibition in Hyperuricemic heart failure patients: the xanthine oxidase inhibition for Hyperuricemic heart failure patients (EXACT-HF) study. Circulation. 2015;131(20):1763-71.

\section{Ready to submit your research? Choose BMC and benefit from:}

- fast, convenient online submission

- thorough peer review by experienced researchers in your field

- rapid publication on acceptance

- support for research data, including large and complex data types

- gold Open Access which fosters wider collaboration and increased citations

- maximum visibility for your research: over $100 \mathrm{M}$ website views per year

At $\mathrm{BMC}$, research is always in progress.

Learn more biomedcentral.com/submissions 